\title{
Neonatal seizures and outcome in NICU
}

O.M.Abdelhaie, E.A.Rateb and E.A.Hosainy

Neonatology, Dept., Faculty of Medicine, Benha Univ., Benha, Egypt

E-Mail:eman.abdelsalam185@gmail.com

\begin{abstract}
Background: Neonatal seizure is a relatively common pediatric emergency and it is critical to determine the etiology and other factors that determine the outcome. Our study aimed to delineate the Clinco-etiologic profile of neonatal seizures and the neurodevelopmental Outcome in a sample of Egyptian newborns. Methods: This prospective cohort study was conducted in Neonatal Intensive Care Units (NICUs) at Banha University Hospital and Benha Children Hospital between January 2018 and December 2020. The study protocol was approved by the Ethical Scientific Committee of Faculty of Medicine, Banha University conferring to the World Medical Association Declaration of Helsinki, and informed consent was obtained from parents/guardians before enrollment in the study. Eligibility criteria were a birth gestational age 37 weeks or less and clinically evident neonatal seizures (i.e., within the first 28 days of life). The diagnosis of clinical neonatal seizures was made by a pediatric neurologist and neonatologist. Our study population consisted of 65 term and preterm infants, of whom 50 neonates $(76.9 \%)$ met the inclusion criteria. All neonates were subjected to detailed history included sex, mode of delivery, gestational age, maternal risk factors, Apgar score at 1 and 5 minutes, seizure onset age, seizure type. Etiology, antiepileptic drugs, cranial ultrasonography findings and outcome of seizures were identified. Seizure types were categorized according to Volpe classification schema, 1 based on the paroxysmal clinical phenomena. It included subtle, clonic, tonic and myoclonic presentations. Results: Hypoxic ischemic encephalopathy was the most common etiology noted and was identified in 14(28.0\%) infants. Second most common was intracranial hemorrhage 11(22.0\%) infants, followed by infection $9(18.0 \%)$. This study showed that, subtle seizures were the most common clinical type of seizures noted in $29(58.0 \%)$ infants followed by clonic type in 11(22.0\%) and tonic type in 9(18.0\%) infants. This study showed that, regarding outcome of the studied neonates: of 50 infants, $25(50.0 \%)$ infants had a normal outcome and $9(18.0 \%)$ infants survived with a neurodevelopmental impairment, while 16(32.0\%) infants died. In the present work, there was highly significant Correlation between clinical type of seizures and Apgar score at 5 minutes. And There was significant association between treatment of cases during admission and clinical type of seizures Conclusion: Hypoxic ischemic encephalopathy is the most common etiology of neonatal seizures. Subtle seizure was the most common pattern in their observation. High risks for unfavorable neurological outcomes. The mortality rate was high.
\end{abstract}

Key words: Neonatal seizures, outcome, NICU.

\section{Introduction}

Neonatal seizure is a relatively common pediatric emergency and it is critical to determine the etiology and other factors that determine the outcome. Even with advanced perinatal care, mortality and morbidity of neonatal seizure remains high. There are a number of problems in diagnosis and management of neonatal seizures underscoring the dynamic nature of the study of neonatal seizures. [1] The incidence of seizures is higher in the neonatal period than in any other period of life and is estimated at approximately three per 1000 live births [2]. Yet their clinical recognition is difficult, therefore true incidence of neonatal seizures is difficult to determine. Seizures are often the first sign of neurological dysfunction in newborn but their clinical expression at this age is quite variable, poorly organized and often subtle [3]. Seizures are a potentially life-threatening problem with a variety of causes. Studies from different low-income countries showed that perinatal asphyxia with hypoxic-ischemic encephalopathy (HIE) is the most common cause. [4] Metabolic abnormalities, infection, intracranial hemorrhage, developmental anomalies, and others like inborn errors of metabolism are rare causes of neonatal seizures. [5] Seizures are one of the immediate neonatal emergencies, where diagnostic and therapeutic plans are necessary because delay in therapy often results in poor neurological outcome [5].Our study aimed to delineate the Clinco-etiologic profile of neonatal seizures and the neurodevelopmental Outcome in a sample of Egyptian newborns.

\section{Subjects and methods}

Study design and population

This prospective cohort study was conducted in Neonatal Intensive Care Units (NICUs) at Banha University Hospital and Banha Children Hospital between January 2018 and December 2020. The study protocol was approved by the Ethical Scientific Committee of Faculty of Medicine, Banha University conferring to the World Medical Association Declaration of Helsinki, and informed consent was obtained from parents/guardians before enrollment in the study. Eligibility criteria were a birth gestational age 37 weeks or less and clinically evident neonatal seizures (i.e., within the first 28 days of life). The diagnosis of clinical neonatal seizures was made by a pediatric neurologist and neonatologist. .Exclusion criteria were cerebral malformation and genetic syndromes. All patients had at least 6 months of neurologic follow-up data. Our study population consisted of 65 term and preterm infants, of whom 50 neonates $(76.9 \%)$ met the inclusion criteria. All 
neonates were subjected to detailed history included sex, mode of delivery, gestational age, maternal risk factors, Apgar score at 1 and 5 minutes, time of admission to NICU and occurrence of jaundice. Seizure types were categorized according to Volpe classification schema' (6) based on the paroxysmal clinical phenomena. It included subtle, clonic, tonic and myoclonic. The primary etiology of the seizure was determined through the clinical history, neuroimaging studies [computed tomography (CT), cranial ultrasonography findings and magnetic resonance imaging (MRI)], and laboratory tests (cbc, electrolytes, ABG, blood glucose, blood and CSF cultures, (TORCH) screen for congenital infection or workup for inborn error of metabolism.. Intrapartum asphyxia required 5-minute Apgar score of _6 and fetal distress. The diagnosis of infection (bacterial or viral) had confirmatory laboratory evidence on CSF or blood culture. Intracranial hemorrhage included epidural, subarachnoid, subdural, parenchymal, and/or intraventricular hemorrhage. Almost all infants had serial cranial ultrasonography examinations. Some had at least one additional modality of imaging, such as cranial CT or MRI.

We divided the etiologies to 7 groupes: (1) Hypoxic ischemic encephalopathy, (2) Intracranial hemorrhage, (3) infection, (4) Inborn error of metabolism, (5) Electrolyte disturbance, (6) Trauma, (7) Miscellaneous

The drug of first choice was phenobarbital at a loading of $20-40 \mathrm{mg} / \mathrm{kg}$ and a maintenance dose of 3 - $8 \mathrm{mg} / \mathrm{kg} /$ day intravenously administered. If the seizures persisted or recurred, then we administered phenytoin at a loading dose of $20 \mathrm{mg} / \mathrm{kg}$ and a maintenance dose of $4-8 \mathrm{mg} / \mathrm{kg} / \mathrm{day}$ intravenously then third line was levetiracetam with loading dose 40 $\mathrm{mg} / \mathrm{kg}$ divided on two doses followed by maintenance dose of $40-60 \mathrm{mg} / \mathrm{kg} /$ day intravenously. The neurologic outcome recorded at the last follow-up was included in the subsequent data analysis. And it was divided to survivors with normal outcome, survivors with late complications and non-survivors.

\subsection{Statistical Analysis}

Data analysis was performed using the software SPSS (Statistical Package for the Social Sciences) version 24. Quantitative variables were described using their means and standard deviations. Categorical variables were described using their absolute frequencies and were compared using Chi square test and fisher exact test when appropriate. Kolmogorov-Smirnov (distribution-type) tests were used to verify assumptions for use in parametric tests. To compare continuous quantitative data of two groups, Mann whitney test (for non-normally distributed data) and independent sample t test (for normally distributed data) were used. The level statistical significance was set at $5 \%(\mathrm{P}<0.05)$. [7]

\section{Results}

We studied group of 50 neonates there were 30 male and 20 female. The mean gestational age was $34.6 \pm 3.2$ weeks. The mean birth weight was $2.2 \pm$ 0.75 . Nine infants were born by vaginal delivery 9 $(18 \%)$ and $41(82 \%)$ by cesarean section Table (1).

Of the 50 study participants, subtle seizures were the most common seizures type $29(58.0 \%)$ followed by clonic seizures $11(22.0 \%)$ and tonic seizures 9(18.0\%) Table (2).

hypoxic ischemic encephalopathy was the most common etiology noted and was identified in 14 $(28.0 \%)$ Followed by intracranial hemorrhage $11(22.0 \%)$ and infection $9(18.0 \%)$ Table (3).

- Regarding anticonvulsant therapy of the studied neonates during admission: Of 50 infants there were $25(50.0 \%)$ infants treated with monotherapy (Phenobarbital only), 10(20.0\%) infants received double therapy (Phenobarbital plus phenytoin) and $15(30.0 \%)$ infants received triple therapy (Phenobarbital, phenytoin and levetiracetam) Table (6).

There were 25(50.0\%) Survivors with normal outcome, 9(18.0\%) Survivors with late complications and $16(32.0 \%)$ non-survivors Table (4).

- There was highly significant Correlation between clinical type of seizures and mean APGAR score at 5 minutes (p value 0.002 ) Table (5).

- There was significant association between treatment of cases during admission and clinical type of seizures ( $\mathrm{p}$ value 0.024 ) Table (6).

Table (1) Perinatal history of the studied neonate.

\begin{tabular}{lcc}
\hline perinatal history & Range & Mean \pm SD \\
\hline Gestational age (weeks) & $29-41$ & $34.6 \pm 3.2$ \\
Birth weight (kg) & $0.96-3.8$ & $2.2 \pm 0.75$ \\
Sex & 30 & 60 \\
Male & 20 & 40 \\
Female & & \\
Mode of delivery & 9 & 18 \\
vaginal delivery & 41 & 82 \\
cesarean section & & \\
\hline
\end{tabular}


Table (2) clinical type of Seizures.

\begin{tabular}{lcc}
\hline Seizures & Range & Mean \pm SD \\
\hline Clinical type & 29 & 58 \\
Subtle & 11 & 22 \\
clonic & 9 & 18 \\
tonic & 1 & 2 \\
Myoclonic & & \\
\hline
\end{tabular}

Table (3) Etiology of the studied neonates.

\begin{tabular}{lcc}
\hline \multicolumn{1}{c}{ Etiology } & Frequency & $\%$ \\
\hline Hypoxic ischemic encephalopathy & 14 & 28.0 \\
Intracranial hemorrhage & 11 & 22.0 \\
infection & 9 & 18.0 \\
Inborn error of metabolism & 4 & 8.0 \\
Electrolyte disturbance & 5 & 10.0 \\
Trauma & 3 & 6.0 \\
Miscellaneous etiologies (Benign neonatal convulsions, & & \\
Neonatal abstinence syndrome, Congenital muscular & & 8.0 \\
dystrophy, mass & 4 & \\
\hline
\end{tabular}

Table (4) Outcome \& late complications among neonates with different types of seizures.

\begin{tabular}{|c|c|c|c|c|c|c|c|}
\hline \multirow{2}{*}{$\begin{array}{l}\text { Outcome\& late } \\
\text { complications }\end{array}$} & \multirow[b]{2}{*}{ TOTAL } & \multirow[b]{2}{*}{$\begin{array}{c}\text { Subtle } \\
\mathbf{n}=\mathbf{2 9}\end{array}$} & \multirow[b]{2}{*}{$\begin{array}{l}\text { Tonic } \\
\mathrm{n}=11\end{array}$} & \multicolumn{3}{|c|}{ Clinical type of seizures } & \multirow[b]{2}{*}{ P-value } \\
\hline & & & & $\begin{array}{c}\text { Clonic } \\
\mathbf{n}=9\end{array}$ & $\begin{array}{l}\text { Myoclonic } \\
\mathbf{n}=1\end{array}$ & FET test & \\
\hline $\begin{array}{l}\text { Survivors with } \\
\text { normal outcome }\end{array}$ & $25(50 \%)$ & 10 & 8 & 7 & 0 & & \\
\hline $\begin{array}{l}\text { Survivors with late } \\
\text { complications: }\end{array}$ & $9(18 \%)$ & 7 & 0 & 2 & 0 & 36.95 & 0.057 \\
\hline Non survivor & $16(32 \%)$ & 12 & 3 & 0 & 1 & & \\
\hline
\end{tabular}

Table (5) Relation between APGAR score \& clinical type of seizure.

\begin{tabular}{lcccccc}
\hline APGAR score & $\begin{array}{c}\text { Subtle } \\
\mathbf{n = 2 9}\end{array}$ & $\begin{array}{c}\text { Tonic } \\
\mathbf{n = 1 1}\end{array}$ & $\begin{array}{c}\text { Clinical type of seizures } \\
\text { Clonic } \\
\mathbf{n}=\mathbf{9}\end{array}$ & $\begin{array}{c}\text { Myoclonic } \\
\mathbf{n = 1}\end{array}$ & F test & P-value \\
\hline $\begin{array}{l}\text { At one minute } \\
\begin{array}{l}\text { Mean } \pm \text { SD } \\
\text { At five minutes } \\
\text { Mean } \pm \text { SD }\end{array}\end{array}$ & $5.27 \pm 1.48$ & $5.54 \pm 1.5$ & $6.66 \pm 1.11$ & 4.00 & 2.56 & 0.06 \\
\hline
\end{tabular}

Table (6) Treatment protocols used for neonates with clinical types of seizures.

\begin{tabular}{|c|c|c|c|c|c|c|c|}
\hline \multirow[b]{2}{*}{ Treatment } & \multirow[b]{2}{*}{ total } & \multicolumn{6}{|c|}{ Clinical type of seizures } \\
\hline & & Subtlen $=29$ & $\begin{array}{l}\text { Tonic } \\
\mathbf{n}=11\end{array}$ & Clonicn=9 & $\begin{array}{c}\text { Myoclonic } \\
n=1\end{array}$ & FETtest & P-value \\
\hline Phenobarbital & $25(50 \%)$ & $10(34.5 \%)$ & $7(63.6 \%)$ & $8(88.9 \%)$ & $0(0 \%)$ & & \\
\hline $\begin{array}{l}\text { Phenobarbital } \\
\text { + phenytoin }\end{array}$ & $10(20 \%)$ & $7(24.1)$ & $1(9.1 \%)$ & $1(11.1 \%)$ & $1(100 \%)$ & & \\
\hline $\begin{array}{l}\text { Phenobarbital } \\
\text { + phenytoin } \\
\text { +levetiracetam }\end{array}$ & $15(30 \%)$ & $12(41.4 \%)$ & $3(27.3 \%)$ & $0(0 \%)$ & $0(100 \%)$ & 12.28 & $0.024 *$ \\
\hline
\end{tabular}




\section{Discussion}

In this study, hypoxic ischemic encephalopathy was the most common etiology noted and was identified in $14(28.0 \%)$ infants. Second most common was intracranial hemorrhage $11(22.0 \%)$ infants, followed by infection $9(18.0 \%)$.

This was in accordance with that reported by Ghanshyambhai et al. [8] who found the most common cause of neonatal seizure was hypoxic ischemic encephalopathy (HIE)

This was in agreement with Baudou et al. [8] who found the frequencies of etiologies of neonatal seizures were: hypoxic-ischemic encephalopathy (HIE) $(\mathrm{n}=91 ; 37 \%)$. In their population, the incidence of each etiology was: $37 \%$ hypoxicischemic encephalopathy, $12 \%$ ischemic infarction, $15 \%$ intracranial hemorrhage, $8 \%$ intracranial infections, $3 \%$ metabolic or electrolyte disorder, $2 \%$ inborn errors of metabolism, 5\% congenital malformations of the central nervous system, and $11 \%$ epileptic syndromes.

This study showed that, $16(32.0 \%)$ of the studied neonates died.

This was higher than that reported by Baudou et al. [9] who found $18.5 \%$ of the studied patients died.

And also, higher than previous publications of Mastrangelo et al. [10] (21\%) and Glass et al. [11] (17\%).

This study showed that, subtle seizures were the most common clinical type of seizures noted in $29(58.0 \%)$ infants followed by clonic type in $11(22.0 \%)$ infants and tonic $9(18.0 \%)$ infants

In agreement with Sabzehei et al. [12] who found regarding terms of clinical type, subtle seizure was the most common type, which was seen in 39 (38.2\%) neonates, followed by tonic in $30(29.4 \%)$, clonic in $27(26.4 \%)$, and myoclonic in $6(5.9 \%)$

Similar results were reported by moayedi et al. and Tekgul et al. [13, 14].

In contrast to these results, Fiaz et al. studied 101 neonates with seizures, of whom $39.6 \%$ had both tonic and clonic seizures [15].

This study showed that, regarding outcome of the studied neonates: of 50 infants, 25(50.0\%) infants had a normal outcome and 9(18.0\%) infants survived with a neurodevelopmental impairment, while 16(32.0\%) infants died.

This is consistent with Lai et al. [16] who found among the 232 enrolled infants, 125 had a normal outcome and 14 had mild functional disability $(59.9 \%)$, and $55(23.7 \%)$ survived with one or more neurodevelopmental impairments and 38 (16.4\%) died. Forty-seven $(23.0 \%)$ of the 204 patients who survived after the first discharge had epilepsy.

Conclusion

Based on the results of the current study, it can be concluded that hypoxic ischemic encephalopathy is the most common etiology of neonatal seizures. Subtle seizure was the most common pattern in their observation. High risks for unfavorable neurological outcomes. The mortality rate was high.

\section{References}

[1] H.Tekgul, K.Gauvreau, J.Soul, L.Murphy, R.Robertson, J.Stewart. The current etiologic profile and neurodevelopmental outcome of seizures in term newborn infants. Pediatrics. Apr.vol.117(4),pp.1270-80,2006.

[2] GM.Ronen, D.Buckley, S.Penney, DL.Streiner. Long-term prognosis in children with neonatal seizures: a population-based study. Neurology. 2007 Nov;69(19):1816-22.

[3] Kumar A, Gupta A, Talukdar B. Clinicoetiological and EEG profile of neonatal seizures. Indian J Pediatr. 2007 Jan;74(1):33-7.

[4] Talebian A, Jahangiri M, Rabiee M, Masoudi Alavi N, Akbari H, Sadat Z. The Etiology and Clinical Evaluations of Neonatal Seizures in Kashan, IRAN. Iran J child Neurol. 2015;9(2):29-35.

[5] Sabzehei MK, Basiri B, Bazmamoun H. The Etiology, Clinical Type, and Short Outcome of Seizures in NewbornsHospitalized in Besat Hospital/Hamadan/ Iran. Iran J child Neurol. 2014;8(2):24-8.

[6] Volpe JJ. Neonatal seizures. In: Volpe JJ, editor. Neurology of the newborn. 5th ed. Philadelphia: WB Saunders; 2008, p ${ }^{r} \cdot r$.e4.)

[7] Levesque, R. SPSS Programming and Data Management: A Guide for SPSS and SAS Users, SPSS Inc. Chicago Ill. PDF ISBN, 2007: 1-56827-390-8.

[8] Ghanshyambhai P, Sharma D, Patel A, Shastri S. To study the incidence, etiology and EEG profile of neonatal seizures: a prospective observational study from India. J Matern Fetal Neonatal Med. 2016;29(4):554-8.

[9] Baudou E, Cances C, Dimeglio C, Hachon Lecamus C. Etiology of neonatal seizures and maintenance therapy use: a 10-year retrospective study at Toulouse Children's hospital. BMC Pediatr. 2019 Apr 29;19(1):136.

[10] Mastrangelo M, Van Lierde A, Bray M, Pastorino G, Marini A, Mosca F. Epilepstic seizures, epilepsy and epieptic syndromes in newborns: a nosological approach of 94 new cases by the 2001 proposed diagnostic scheme for people with epileptic seizures and epilepsy. Seizure. 2005;14(5):304-11.

[11] Glass HC, Pham TN, Danielsen B, Towne Glidden D, Wu YW. Antenatal and intrapartum Risk Factors for Seizures in Term Newborns:A Population-Based Study, California 1998-2002. Pediatr Neurol. 2012;46(2):111-5.

[12] Sabzehei M, Basiri B, Bazmamoun H. The etiology, clinical type, and short outcome of seizures in Newborns Hospitalized in Besat Hospital/Hamadan/Iran. Iran J Child Neurol 2014;8(2):24-28. 
[13] Moayedi AR, Zakeri S, Moayedi F. Neonatal seizures: Etiology and type. Iran J child Neurol . 2007;23(6).

[14] Tekgul H, Gauvreau K, Soul J, Murphy L, Robertson R, Stewart J et al. The current etiologic profile and neurodevelopmental outcome of seizures in term newborn infants. Pediatrics. 2006;117:1270-80.

[15]Faiz N, Malik M, Azam M, Afzal U. Etiology and type of neonatal seizures. Ann Pak Inst Med Sci. 2009;5(2):77-86.

[16] Lai YH, Ho CS, Chiu NC, Tseng CF, Huang YL. Prognostic factors of developmental outcome in neonatal seizures in term infants. Pediatr Neonatol 2013;54(3):166-72. 